BNL-112575-2016-JA

\title{
HIGH-TEMPERATURE ANNEALING OF PROTON IRRADIATED BERYLLIUM: A DILATOMETRY-BASED STUDY
}

Nicholas Simos, Mohamed Elbakhshwan, Zhong Zhong, Sanjit Ghose, Ilyas Savkliyildiz

Submitted to Journal of Nuclear Materials

August 2016

Nuclear Sciences \& Technology Department

Brookhaven National Laboratory

\author{
U.S. Department of Energy \\ USDOE Office of Science (SC), \\ Nuclear Physics (NP) (SC-26)
}

Notice: This manuscript has been authored by employees of Brookhaven Science Associates, LLC under Contract No.DE-SC0012704 with the U.S. Department of Energy. The publisher by accepting the manuscript for publication acknowledges that the United States Government retains a non-exclusive, paid-up, irrevocable, world-wide license to publish or reproduce the published form of this manuscript, or allow others to do so, for United States Government purposes. 


\section{DISCLAIMER}

This report was prepared as an account of work sponsored by an agency of the United States Government. Neither the United States Government nor any agency thereof, nor any of their employees, nor any of their contractors, subcontractors, or their employees, makes any warranty, express or implied, or assumes any legal liability or responsibility for the accuracy, completeness, or any third party's use or the results of such use of any information, apparatus, product, or process disclosed, or represents that its use would not infringe privately owned rights. Reference herein to any specific commercial product, process, or service by trade name, trademark, manufacturer, or otherwise, does not necessarily constitute or imply its endorsement, recommendation, or favoring by the United States Government or any agency thereof or its contractors or subcontractors. The views and opinions of authors expressed herein do not necessarily state or reflect those of the United States Government or any agency thereof. 


\title{
HIGH-TEMPERATURE ANNEALING OF PROTON IRRADIATED BERYLLIUM - A DILATOMETRY-BASED STUDY
}

\author{
Nicholas Simos $^{1^{*}}$, Mohamed Elbakhshwan ${ }^{1}$, Zhong Zhong $^{1}$, Sanjit Ghose ${ }^{1}$, Ilyas Savkliyildiz ${ }^{2}$ \\ ${ }^{1}$ Brookhaven National Laboratory, Upton, NY 11973, USA \\ ${ }^{2}$ Rutgers University
}

*Corresponding author:

Nicholas Simos

Brookhaven National Laboratory

Upton, NY 11973

(E-mail: simos@bnl.gov, telephone: 631-344-7229, fax: 631 344-7650) 


\title{
HIGH-TEMPERATURE ANNEALING OF PROTON IRRADIATED BERYLLIUM A DILATOMETRY-BASED STUDY
}

\author{
N. Simos ${ }^{1 *}$, M. Elbakhshwan, Z. Zhong, S. Gosh, I. Savkliyildiz \\ ${ }^{1}$ Brookhaven National Laboratory, Upton, NY 11973, USA \\ ${ }^{1}$ Rutgers University
}

\begin{abstract}
:
S-200F grade beryllium has been irradiated with $160 \mathrm{MeV}$ protons up to $0.610^{20} \mathrm{~cm}^{-2}$ fluence and irradiation temperatures in the range of $100-200^{\circ} \mathrm{C}$. To address the effect of proton irradiation on dimensional stability, a very important parameter in its consideration in fusion reactor applications, and to simulate high temperature irradiation conditions, multi-stage annealing using high precision dilatometry to temperatures up to $740^{\circ} \mathrm{C}$ were conducted in air. X-ray diffraction studies were also carried out to compliment the macroscopic thermal study and offer a microscopic view of the irradiation effects on the beryllium crystal lattice. The overall objective was to qualify and quantify the competing dimensional change processes taking place at elevated temperatures namely manufacturing defect annealing, lattice parameter recovery, transmutation ${ }^{4} \mathrm{He}$ and ${ }^{3} \mathrm{H}$ diffusion and swelling and oxidation kinetics. The study revealed the presence of manufacturing porosity in the beryllium grade, the oxidation acceleration effect of irradiation including the discontinuous character of oxidation advancement, the effect of annealing duration on the recovery of lattice parameters recovery and the triggering temperature for transmutation gas diffusion leading to swelling.
\end{abstract}

KEYWORDS: Irradiation damage, high temperature annealing, oxidation, transmutation gas, beryllium

\footnotetext{
${ }^{*}$ Work performed under the auspices of the US DOE
} 


\section{Introduction}

Beryllium exhibiting excellent neutron multiplication and moderation properties in conjunction with its good thermal properties is under consideration for use as plasma facing material in fusion reactors and as a very effective neutron reflector in fission reactors. While the relatively low thermal neutron absorption cross section makes beryllium the material of choice for reactor reflectors long term exposure to neutrons results in gradual buildup of transmutation gases such as ${ }^{4} \mathrm{He}$ and ${ }^{3} \mathrm{H}$ and whose buildup is linked to swelling and degradation in its mechanical properties. The irradiation generated transmutation gases exhibit low solubility leading to super-saturation of the beryllium matrix and eventual precipitation into helium bubbles that coalesce inducing swelling. In addition to its consideration as plasma facing material in fusion reactors and as reflector in fission reactors beryllium has been also considered and evaluated as spallation neutron source target and as pion source target in a number of high power accelerator initiatives. An comprehensive summary of physical, mechanical and nuclear properties unirradiated beryllium properties are presented by K. A. Walsh [1] where the physical, elastic and crystallographic properties as functions of temperature are described.

To understand the effect of proton irradiation on dimensional stability, a crucial parameter in its consideration in fusion reactor applications, and to simulate high temperature irradiation conditions, multi-stage annealing using high precision dilatometry to temperatures up to $740^{\circ} \mathrm{C}$ were conducted in air.

To that end S-200F grade beryllium has been irradiated with energetic protons $(160 \mathrm{MeV})$ from the Brookhaven National Laboratory Linac to $1.210^{20} \mathrm{~cm}^{-2}$ peak fluence and irradiation temperatures in the range of $100-200^{\circ} \mathrm{C}$ followed by post-irradiation examination studies. X-ray diffraction studies were also carried out to compliment the macroscopic thermal study and offer a microscopic view of the irradiation effects on the beryllium crystal lattice. The overall objective was to qualify and quantify the competing dimensional change processes taking place at elevated temperatures namely manufacturing defect annealing, lattice parameter recovery, transmutation ${ }^{4} \mathrm{He}$ and ${ }^{3} \mathrm{H}$ diffusion and swelling and oxidation kinetics. The study revealed the presence of manufacturing porosity in the beryllium grade, the oxidation acceleration effect of irradiation including the discontinuous character of oxidation advancement, the effect of annealing duration on the recovery of lattice parameters recovery and the triggering temperature for transmutation gas diffusion leading to swelling.

High sensitivity dilatometry is a powerful technique to capture the dilatation of a sample as a function of temperature and time in a very precise manner. High resolution capabilities of the employed instrument can reveal phase transformations and other kinetics that are triggered by temperature. In this study a high precision LINSEIS dual rod dilatometer (sub-nm resolution) was used to study the response of beryllium samples, both irradiated and unirradiated for up to $740^{\circ} \mathrm{C}$ temperatures in a multi-stage annealing thermal cycles with isotherms up to $10 \mathrm{hrs}$.

The objective was that annealing of beryllium samples irradiated at low temperature will provide an interesting method to mimic the effects of high temperature irradiation and also offer the means to study the kinetics of transmutation gas diffusion, swelling, lattice parameter recovery and oxidation. The effects of proton irradiation on a beryllium reflector on microstructural changes and evolution have been explored in other studies [2] as part of the effort to emulate the effects of neutron irradiation on beryllium. In [2] S200-F beryllium was irradiated with low energy protons $(120 \mathrm{KeV})$ and fluence of $2.0 \times 10^{18}$ ions $/ \mathrm{cm}^{2}$ at room temperature. It was assessed in [2] that due to proton irradiation voids preferentially developed at the interface between the beryllium matrix and the $\mathrm{BeO}$ and that the existence of $\mathrm{BeO}$ will accelerate the embrittlement and swelling of beryllium. 
A number of studies have been conducted with interest in the dimensional stability affected by manufacturing defects, neutron irradiation and thermal annealing, oxidation as well as diffusion kinetics of transmutation gases.

The impact of impurities and in particular the role of manufacturing defects of manufacturing process of beryllium on the volumetric stability or the porosity state has captured the attention of studies [3] where S200-F beryllium grade was studied in its unirradiated state along with neutron irradiated S200-E and confirmed the presence of fabrication porosity and its evolution with temperature.

Leenaers, et al. [4] performed post-neutron irradiation microstructural studies on S-200-E grade Be manufactured by vacuum hot-pressing that has been subjected to a temperature of approximately $50^{\circ} \mathrm{C}$ and to a fission neutron fluence of $5.32 \cdot 10^{22} \mathrm{n} / \mathrm{cm}^{2}$. Annealing was performed on the irradiated beryllium samples at 500, 750 and $900^{\circ} \mathrm{C}$ for periods ranging between $50 \mathrm{~h}$ and three months. Swelling and porosity were evaluated and were correlated to the diffusion kinetics of ${ }^{4} \mathrm{He}$ and ${ }^{3} \mathrm{H}$. Their microstructural analyses showed a clear evolution in bubble growth and He diffusion towards the grain boundaries where the bubbles coalesce. They assessed complete release of ${ }^{4} \mathrm{He}$ is at temperatures $>750^{\circ} \mathrm{C}$ resulting in a plateau of beryllium swelling. They further deduced that the microstructural changes are mainly temperature driven and observed that only at high annealing temperature the influence of the annealing time is important.

P. Vladimirov and co-workers [5] investigated beryllium reflector fragments irradiated for 15 years in the $\mathrm{BR} 2$ research reactor at temperatures below $120^{\circ} \mathrm{C}$ and containing about 2 at. \% helium was vacuum annealed at two temperatures and various annealing times. Gas-induced porosity developed as a result of annealing was investigated using synchrotron X-ray micro-tomography and important insights into the kinetics of the gas bubble growth. As pointed out above and in establishing the unirradiated reference for beryllium S200-F grade was used.

A. Khomutov, et al [6] summarized results on neutron-irradiated beryllium under consideration for fusion reactors (ITER). They conclude that after irradiation at 70 and $200^{\circ} \mathrm{C}$ up to (1.4-3.9) $10^{22} \mathrm{~cm}^{-2}$, swelling ranged from $0.2 \%$ to $1.5 \%$ and gradually increased with the neutron dose. The important conclusion reached in this study was that no strict dependence of swelling on irradiation temperature was observed. An important point with direct relevance to this study is made in their summary regarding the mobilization of transmutation gases that will be generated during proton irradiation (expected to be higher due to highly energetic protons as compared to neutrons). Mobilization of implanted tritium occurs in two ways. One is diffusion, which is slow; the other is a non-diffusive burst release. The potential for tritium "burst" mobilization from beryllium depends on temperature and microstructure, which itself depends on temperature, time at temperature, neutron damage/swelling and porosity. Normally, burst releases are not seen below $600^{\circ} \mathrm{C}$ and occur following an annealing time of several hours. They note that at ITER operating temperatures, implanted tritium never diffuses deep into beryllium during a thermal excursion event, its mobility increases and some of the implanted tritium diffuses into the bulk of the material and becomes trapped. From the mobilization point of view, the neutron-bred tritium behaves as trapped tritium as well. At temperatures $<500^{\circ} \mathrm{C}$ trapped tritium is not mobilized from beryllium in any significant amount. 
V.P. Chakin and co-workers [7] investigated neutron irradiation influence on the dimensional stability of beryllium by studying the radiation damage of the TE-56 beryllium grade manufactured by hot extrusion and irradiated in the SM reactor at the temperatures of $70^{\circ} \mathrm{C}$ and $200^{\circ} \mathrm{C}$ up to neutron fluence of $(1.3-$ 14.2) $10^{22} \mathrm{n} / \mathrm{cm}^{2}(\mathrm{E}>0.1 \mathrm{MeV})$. Dimensional change measurements and X-ray analyses were conducted revealing that dimensional changes occurs a result of the superposition of two processes - radiation growth and anisotropic swelling. In addition, beryllium crystal lattice parameter changes as a function of neutron fluence were reported.

The oxidation kinetics of beryllium and its connection with temperature have been explored through a number of studies. In [1] a compiled summary of beryllium in gaseous atmospheres is presented that includes oxygen and air with experimental results from high-temperature oxidation of beryllium in air up to the melting temperature. It is reported that at a given temperature there exists a threshold time above which the initial low oxidation rate is followed by much higher rate. The threshold time reduces with increasing temperature. Also reported that epitaxial growth is observed between 300 and $400^{\circ} \mathrm{C}$ while up to $600^{\circ} \mathrm{C}$ randomly oriented beryllium oxide is observed followed by random growth between 600 and $800^{\circ} \mathrm{C}$. The type of beryllium plays a significant role in its resilience to oxidation.

C. Tomastik et al. [8] investigated the interaction of beryllium with air at elevated temperatures up to $600^{\circ} \mathrm{C}$ on a microscopic level, using a high resolution Auger electron microscope. They assessed, based on their experimental observations, that diffusion of oxygen from the surface into the bulk has not detected up to $390^{\circ} \mathrm{C}$ noting that a thin protective oxide film forms at $390^{\circ} \mathrm{C}$, while at $500^{\circ} \mathrm{C}$ oxidation starts to enter into the grain boundaries. In their study they established that growth of the oxide thickness at $390^{\circ} \mathrm{C}$ follows the square root of time while at the higher temperatures $500^{\circ} \mathrm{C}$ and $600^{\circ} \mathrm{C}$ the oxide growth is accelerated. In the present study, prompted by these threshold temperatures we evaluated the kinetics at $390^{\circ} \mathrm{C}$ but also explored the $320^{\circ} \mathrm{C}$ isotherm to investigate the volumetric change (if any) that might be noticeable at even lower temperatures in conjunction with irradiation effects. A. Khomutov et al, [6], also referred to studies of beryllium pebbles on chemical reactivity with air and steam in the temperature range $300-1000^{\circ} \mathrm{C}$ that were performed in the Belgian Nuclear Research Institute. These tests have shown that at temperatures $<700^{\circ} \mathrm{C}$, the kinetics is approximately parabolic and is associated with the growth of a protective oxide layer. Above $700^{\circ} \mathrm{C}$, the kinetics is accelerating-linear and oxidation is non-protective. D. Aylmore [9] studied the kinetics of the oxidation of French Flake beryllium in dry oxygen for 300 -hour periods at temperatures in the range $500-700^{\circ} \mathrm{C}$. This study concluded that, oxidation does not, in contrast to previously reported work, follow a parabolic rate law. This study also observed discontinuities in the oxidation curves attributed to the formation of micro-cracks sufficient to admit molecular oxygen which subsequently undergo healing and closure. It revealed that for temperatures up to and including $650^{\circ} \mathrm{C}$, the oxidation is protective while at $750^{\circ} \mathrm{C}$ the rate first decreases and then increases with time, indicating a breakaway reaction and subsequent non-protective oxidation.

Post neutron-irradiation annealing and recovery of crystal lattice parameters of $\mathrm{BeO}$ were studied in [1016]. Specifically, D. G. Walker and co-workers addressed the effect of post irradiation annealing on the lattice thermal expansion of $\mathrm{BeO}$. The objective was to determine whether the anisotropic lattice expansion induced by irradiation had any significant effect on the lattice coefficients of thermal expansion of beryllium oxide. What was shown in [ ] is that both $\mathrm{c}$ and a parameters increase with fluence in $\mathrm{BeO}$ and that complete recovery of $c$ and $a$ lattice parameters is achieved in the range of $1200-1400^{\circ} \mathrm{C}[10]$.

Based on reported experience with beryllium oxidation and the breakaway potential which was reported to occur above $750^{\circ} \mathrm{C}$ [9] and accelerate [8] above similar temperature thresholds high temperature annealing to temperatures up to and including $740^{\circ} \mathrm{C}$ were performed as part of this study and the various mechanisms inducing dimensional changes were studied based on high sensitivity dilatometry. The selected temperature threshold was to eliminate the potential of a breakaway process in irradiated beryllium anticipating that proton irradiation both accelerates the effect due to the large anisotropy it 
exhibits resulting in micro-cracking at high temperatures that induce large stresses in the beryllium lattice and in turn a conducive path to the oxidation front. Prior to conducting the high temperature annealing of irradiated beryllium X-ray diffraction experiments were performed to assess the microstructural state of the material including the large anisotropy. Reported in the body of the paper are (a) experimental details, (b) high temperature annealing and discussion of the processes triggered by temperature such as oxidation, lattice parameter recovery, swelling from diffusion of transmutation gasses and manufacturing defects, (c) excerpt x-ray diffraction analysis results that are relevant to the volumetric change processes and finally (d) and overall assessment of attempt to emulate irradiation and response of beryllium at high temperatures relying on low temperature irradiation via high temperature annealing. 


\section{Experimental}

\subsection{Sample Preparation}

Extruded S-200-F grade beryllium (Brush-Wellman) was used in the experiment in the form of specially designed samples that were to facilitate thermal analysis $(29 \mathrm{~mm} \times 3 \mathrm{~mm} \times 3 \mathrm{~mm})$ and X-ray diffraction $(42 \mathrm{~mm} \times 1.5 \mathrm{~mm} \times 1.0 \mathrm{~mm})$. According to the manufacturer the composition of the S-200F Beryllium grade consisted of $\mathrm{Be} \geq 98.5 \%$; $\mathrm{BeO} \leq 1.5 \% ; \mathrm{C} \leq 0.15 \%$; $\mathrm{Al}<\leq 0.10 \%$; $\mathrm{Fe} \leq 0.13 \%$; (traces $\mathrm{Mg}$, Si, others). The two types of geometry samples were integrated into an array and were inserted into a special capsule for irradiation. No surface treatment was conducted prior or after irradiation during thermal analysis, oxidation and X-ray diffraction on the beryllium samples. All beryllium samples, as received and irradiated, were encapsulated in Kapton tape for X-ray diffraction analysis at the X17-A and X17-B beamlines of the BNL synchrotron facility.

\subsection{Proton Irradiation Experiment}

An integrated set of beryllium specimens of both geometries formed an irradiation array and together with a number of other test materials were inserted in the path of the $200 \mathrm{MeV}$ protons from the BNL Linac. The energy of protons incident on the beryllium array was estimated to be $160 \mathrm{MeV}$ and the total flux of protons $\sim 5.2710^{20}$ (integrated beam current $\sim 23,453 \mu$ A-hours). The proton beam exhibited a Gaussian transverse profile with $\sigma_{x}=\sigma_{y}=7.2 \mathrm{~mm}$ and had an x-y offset from the center of the array. Special nickel foils integrated into the irradiation assemblies were analyzed and helped establish the beam spot size, shape and position during irradiation. Because monitoring of the irradiation temperature during beam exposure was not feasible due to the hermetically sealed configuration for the sake of medical isotope production downstream of the test material array, the information on the shape and position of the numerical transport/thermal analyses were utilized to deduce irradiation temperatures and the fluence profile for the array of samples. Using the transport codes FLUKA [17, 18] and MCNPX [19] the energy deposition distribution and damage in DPA (Displacements-per-Atom) were deduced. The beryllium sample array in addition to the protons was also exposed to a neutron flux from the spallation process in the upstream test materials. The spallation neutron flux, however, was at least two orders of magnitude lower that the flux of the primary protons and therefore the irradiation damage observed in PIE stems primarily from protons. The energy deposited (in the Beryllium array is calculated to be of the order of $250 \mathrm{~W} / \mathrm{cm}^{3}$ (peak) and the irradiation temperature profile ranged between $100-200^{\circ} \mathrm{C}$.

In the thermal annealing experiments two (2) unirradiated beryllium samples are used as reference. One of the unirradiated samples underwent thermal cycling prior to the high temperature annealing to $300^{\circ} \mathrm{C}$ followed by thermal cycles to $600^{\circ} \mathrm{C}$ at a rate of $2^{\circ} \mathrm{C} / \mathrm{min}$. The goal was to establish the identical reference or basis for comparison with the irradiated samples which experienced the same thermal treatment prior to high temperature annealing. The second unirradiated sample (as received) was only used in high temperature annealing.

Four (4) beryllium samples that were irradiated with protons during the irradiation experiment were utilized in the study. Owed to their different position in the array each was exposed to different fluence. The samples ranged in proton fluence from 0.18 to $0.6010^{20} \mathrm{p} / \mathrm{cm}^{2}$. The primary objective was to depict and delineate through the annealing studies the differences in the crystal lattice damage (based on the recovery kinetics) the effect of fluence as well as the impact on oxidation.

\subsection{Post-irradiation analysis}

The post irradiation evaluation (PIE) of the beryllium array was multi-faceted and it included macroscopic and microscopic evaluation of the effects of proton irradiation on key properties of 
beryllium. The macroscopic assessment, in addition to the high temperature annealing that is the subject of this paper included irradiation effects on stress-strain behavior and ductility loss, thermal expansion coefficient variation. Microstructural effects of irradiation combined with four-point-bending stress including beryllium crystal evolution, deformation, post-fracture lattice state and anisotropy were studied using monochromatic and white high energy synchrotron X-ray beams using XRD and EDXRD techniques. Relevant results of the microscopic studies are integrated in this paper as basis in explaining the macroscopic observations of the deformation of irradiated and unirradiated beryllium stemming from its hcp lattice crystal structure.

\section{Results}

Using the horizontal, two-rod LINSEIS high resolution dilatometer, a comprehensive thermal analysis was performed that consisted of thermal cycling of all four irradiated and of one as-received followed by multi-stage high temperature annealing.

\subsection{Unirradiated Beryllium}

Shown in Figure 1 is the multi-isotherm annealing of unirradiated beryllium (10 isotherms). The experiment involved 6-hour dwell times for the different temperature levels up to and including $700^{\circ} \mathrm{C}$, $730^{\circ} \mathrm{C}$ and a 10 -hour dwell time at the $740^{\circ} \mathrm{C}$ isotherm. Goal was to qualify and quantify the volumetric change that occurs as a result of manufacturing defects in the microstructure and porosity and their evolution or annealing as a function of temperature. Figure 2 depicts the isotherms of $390^{\circ} \mathrm{C}, 500^{\circ} \mathrm{C}$ and $600^{\circ} \mathrm{C}$ during the heating part of the long thermal cycle. It is apparent that at over the $390^{\circ} \mathrm{C}$ and $500^{\circ} \mathrm{C}$ isotherms the volume is stable with only indications of oxidation bumps (as will be discussed later in more detail). At temperatures $\geq 600^{\circ} \mathrm{C}$ beryllium undergoes contraction during the heating part of the annealing cycle with clear annealing of pre-existing defects in the microstructure. As shown in Figure 3 and over the isotherms of $700^{\circ} \mathrm{C}, 740^{\circ} \mathrm{C}$ and $730^{\circ} \mathrm{C}$ (cooling) the high rate of volumetric contraction reduces significantly in post $740^{\circ} \mathrm{C}$ annealing and the as received, not pre-treated beryllium exhibits similar behavior to the pre-thermally cycled one. This is clearly depicted in Figure 4 where the dimensional changes over the $730^{\circ} \mathrm{C}$ and $600^{\circ} \mathrm{C}$ isotherms of the cooling phase of the annealing are shown. As observed in Figures 1, 3 and 4 that compare the as-received and the thermally treated beryllium the previously treated beryllium experiences higher effective volumetric expansion during the heating phase of the cycle. This is explained by the fact that the pre-treatment with thermal cycles up to $600^{\circ} \mathrm{C}$ have eliminated defects in the microstructure and the matrix expands based on the physical properties of beryllium. In the as-received case input energy (heat) is spent for it to grow into the preexisting defects or pores thus leading to an equivalent smaller volumetric change registered by the dilatometer. During the cooling phase of the thermal annealing cycle as shown in Figure 4 the two samples have experienced annealing at the same highest temperature $\left(740^{\circ} \mathrm{C}\right)$ and so they respond very similarly. It is important to note that regardless of the pre-treatment the dimensional change over isotherms $\leq 600^{\circ} \mathrm{C}$ are almost identical and are driven by oxidation as revealed by the discontinuous nature of the traces. Further, demonstrated in Figure 4 is (a) the influence of annealing time in defect-annealing at $730^{\circ} \mathrm{C}$ and (b) the behavior at subsequent lower annealing temperature of $600^{\circ} \mathrm{C}$ where residual manufacturing defect evolution is similar for both pre-treated and as received beryllium.

Figure 5 depicts the behavior of unirradiated and untreated beryllium following 10-hour dwell time at the peak temperature of $740^{\circ} \mathrm{C}$ at various lower isotherms. Important to point out is the fact that at $730^{\circ} \mathrm{C}$ the remaining defect annealing dominates over the oxidation process which is apparent over the $600^{\circ} \mathrm{C}$ and $500^{\circ} \mathrm{C}$ isotherms. At $390^{\circ} \mathrm{C}$ the material is stable with indications of small oxide layer development. This is in agreement with the findings in [8] where $390^{\circ} \mathrm{C}$ was established as the temperature when thin oxide layer of $\sim 20 \mathrm{~nm}$ begins to form on the beryllium sample they studied and $550^{\circ} \mathrm{C}$ is the temperature when oxidation starts to enter into the grain boundaries. 

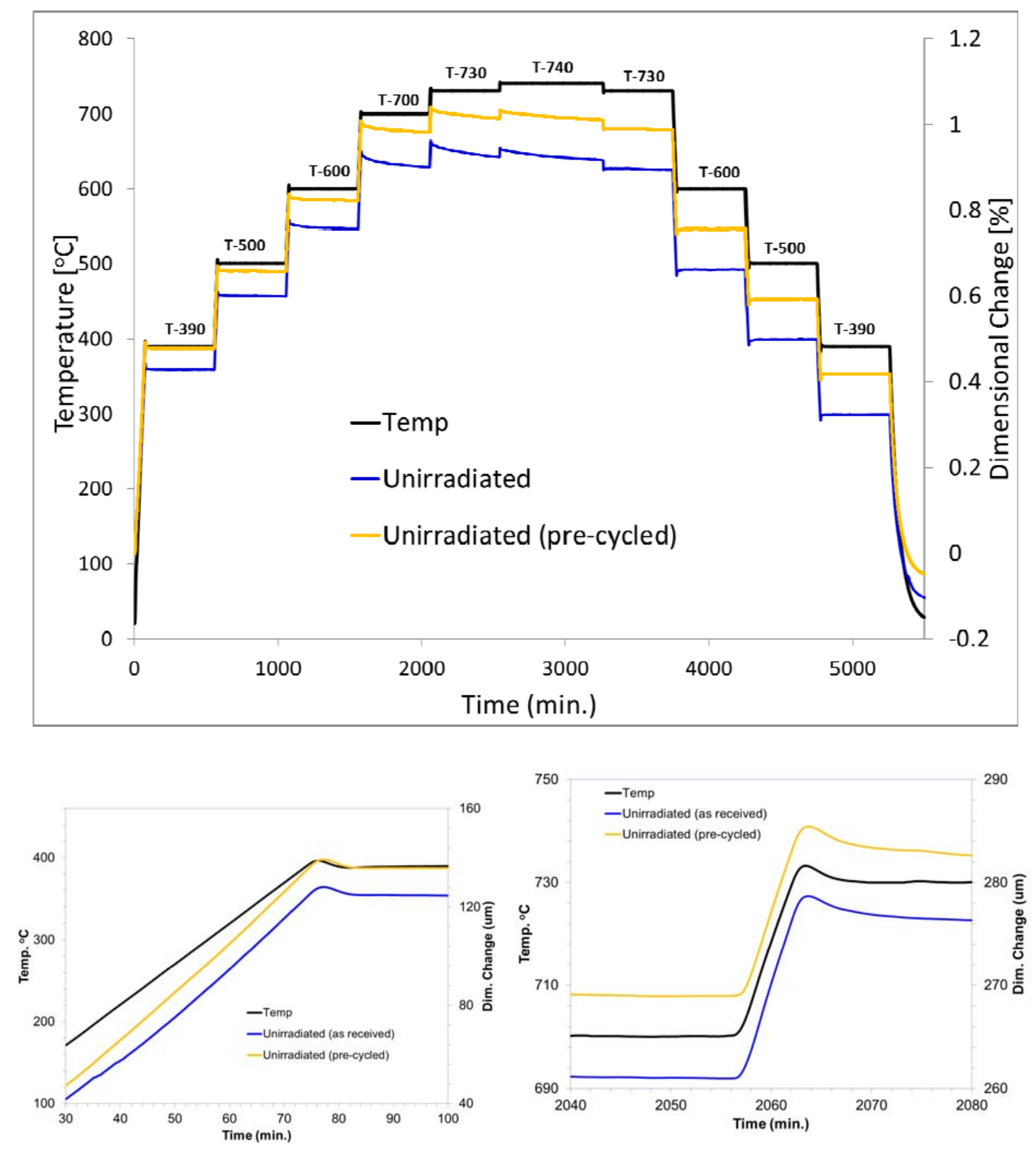

Figure 1: Multi-isotherm annealing cycle of unirradiated beryllium and recovery of manufacturing defects and porosity 

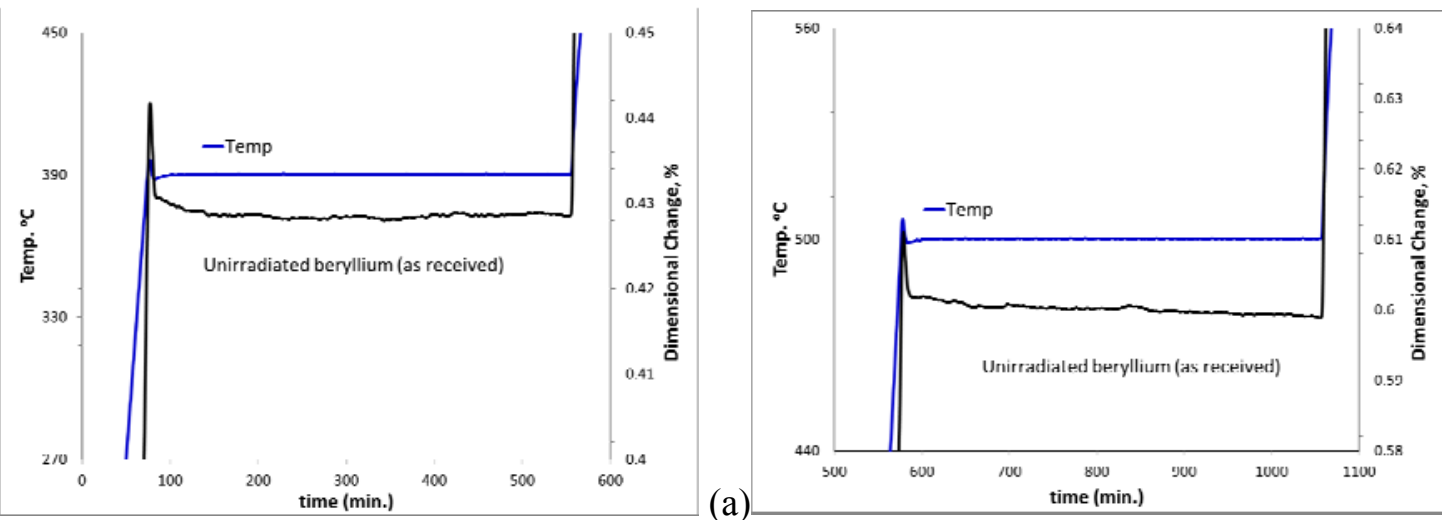

(b)

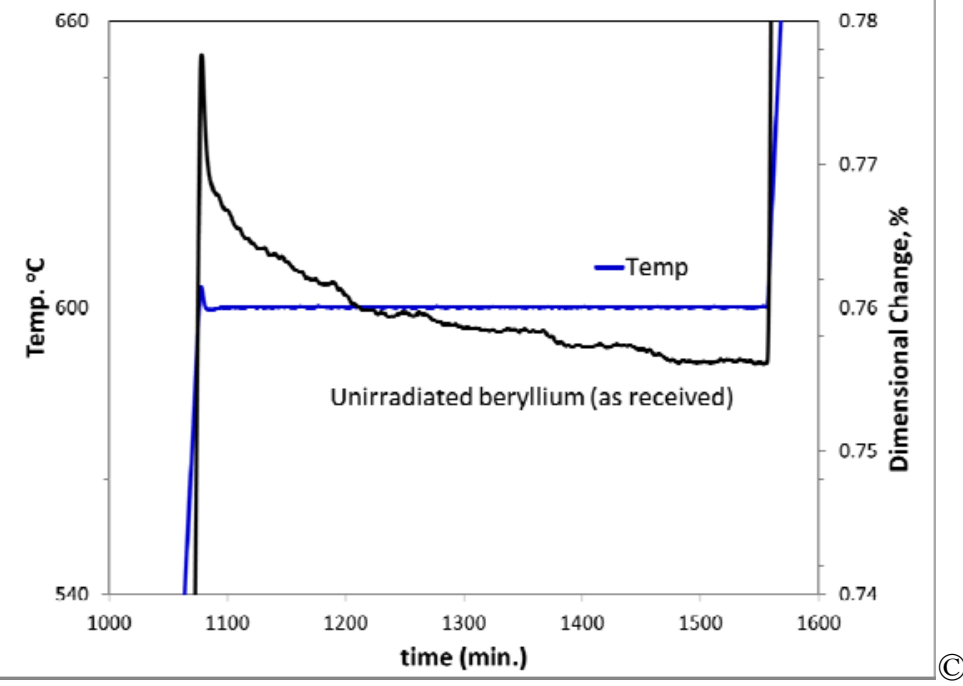

Figure 2: Dimensional stability and manufacturing defect annealing of as-received beryllium to temperatures up to $600^{\circ} \mathrm{C}$. (a) and (b) corresponding to 390 and $500^{\circ} \mathrm{C}$ isotherms show dimensional stability of the as-received S-200F beryllium. (c) Indicates porosity changes accompanied by an effective volumetric contraction due to microstructural expansion into pre-existing pores at $600^{\circ} \mathrm{C}$.
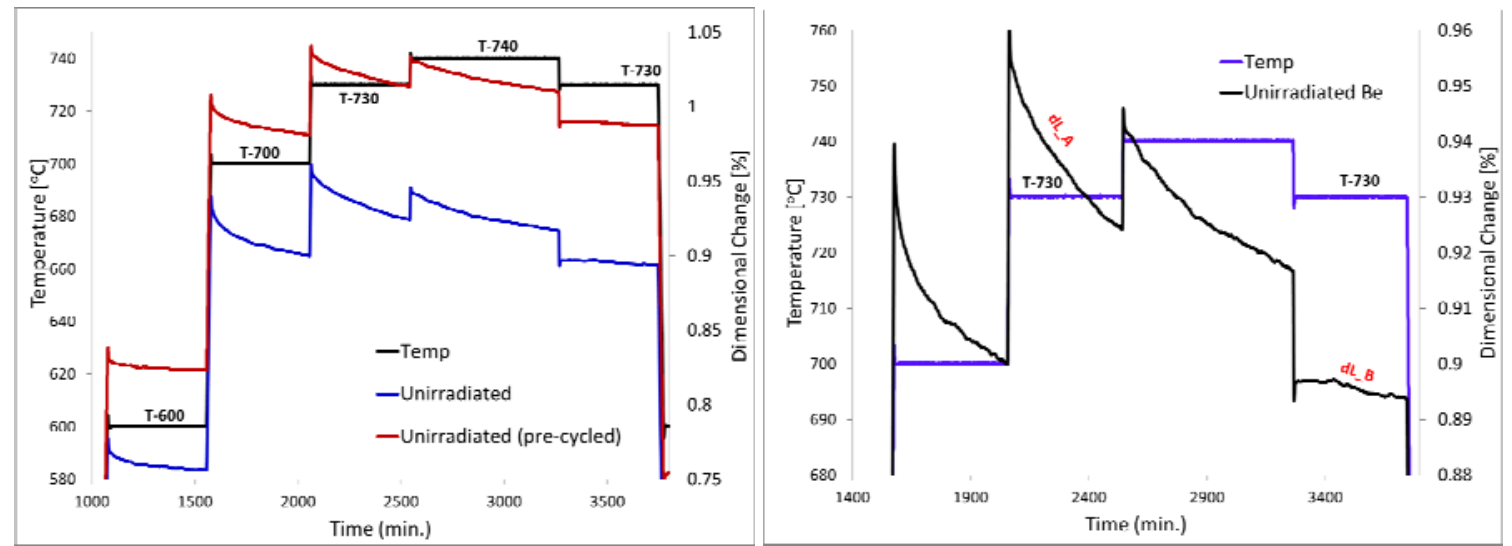

Figure 3: Thermal annealing of unirradiated beryllium with $6-\mathrm{hr}$ and $10-\mathrm{hr}$ isotherms to $740^{\circ} \mathrm{C}$. Shown (left) is the behavior of pre-treated and as received beryllium at temperatures $\geq 600^{\circ} \mathrm{C}$. dL-A and dL-B (right) is the dimensional change behavior of as-received beryllium over the same isotherm $\left(730^{\circ} \mathrm{C}\right)$ observed prior and after annealing for 10 hours at the $740^{\circ} \mathrm{C}$ isotherm. 

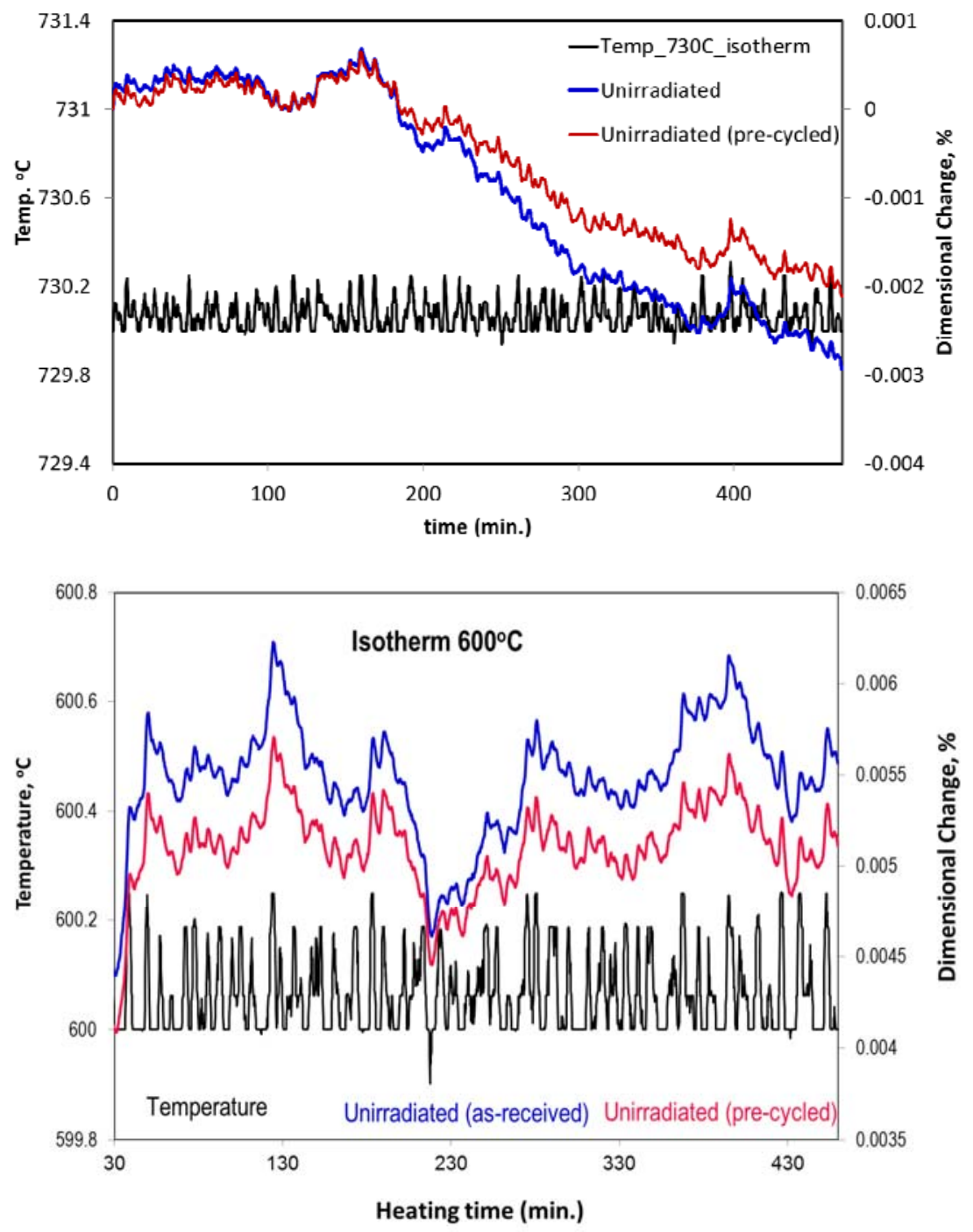

Figure 4: Dimensional changes in unirradiated beryllium (as received and thermally cycled) at $730^{\circ} \mathrm{C}$ (top) and subsequently $600^{\circ} \mathrm{C}$ (bottom) observed during the cooling phase of the multi-isotherm cycle depicted in Figure 1. 


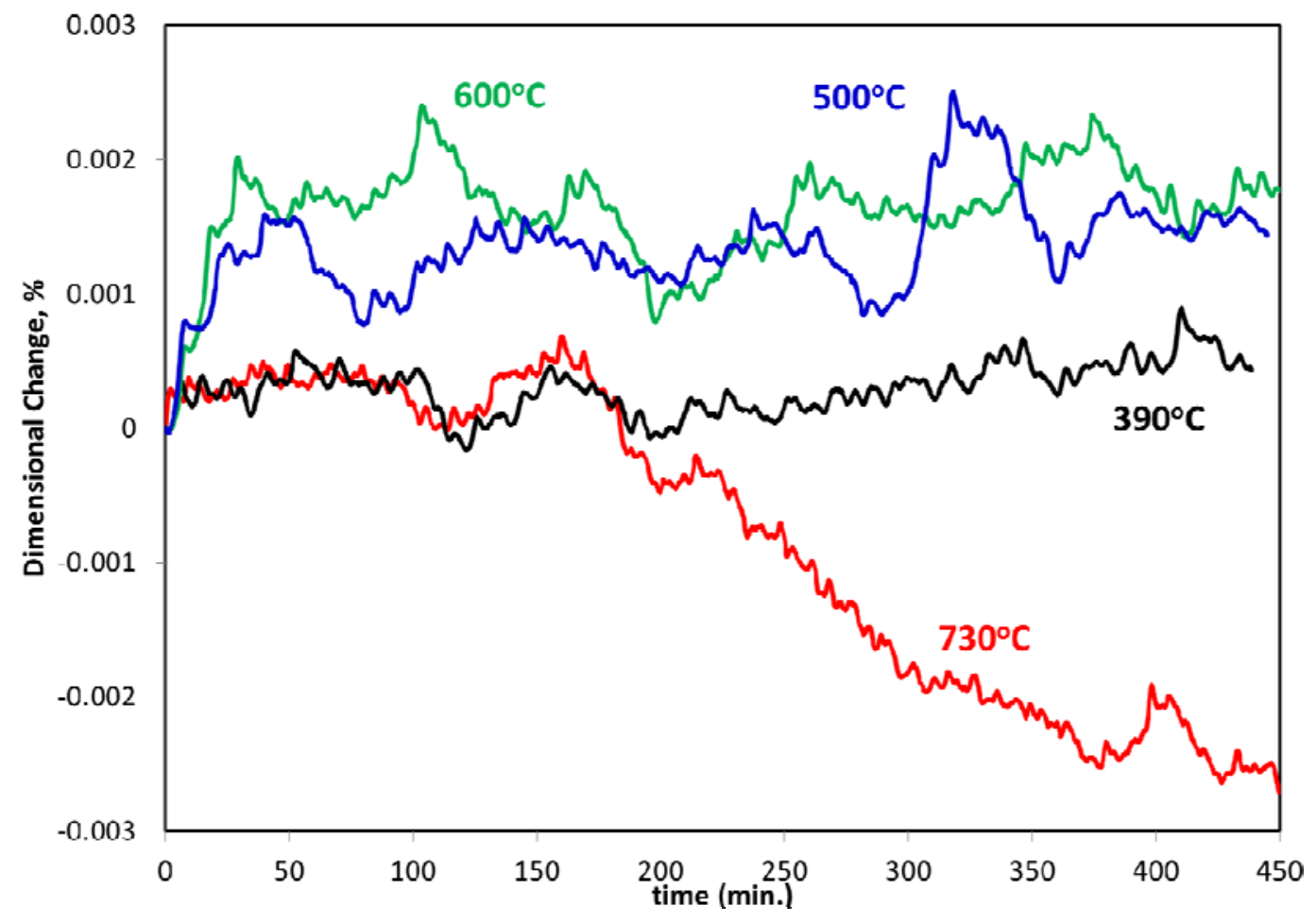

Figure 5: Comparison of dimensional changes in as-received, un-treated beryllium over isotherms. It should be noted that $730^{\circ} \mathrm{C}$ occurs first in the sequence followed by 600,500 and $390^{\circ} \mathrm{C}$. 


\subsection{Irradiated Beryllium}

The four (4) proton-irradiated beryllium samples ranging in fluence between 0.18 and $0.610^{20} \mathrm{~cm}^{-2}$ had all undergone thermal cycling up to $600^{\circ} \mathrm{C}$ prior to high temperature annealing to establish the thermal expansion coefficient as a function of temperature. The irradiation temperature as noted previously was estimated to be $\leq 200^{\circ} \mathrm{C}$ with the $\sim 200^{\circ} \mathrm{C}$ corresponding to the sample with the peak fluence. Figure 6 depicts the dimensional response of the irradiated beryllium sample with the peak fluence over two (2) back-to-back high temperature annealing cycles (RUN-1 \& RUN-2 respectively). RUN-1 consisted of isotherms at $320^{\circ} \mathrm{C}$, at $390^{\circ} \mathrm{C}$ at $500^{\circ} \mathrm{C}, 600^{\circ} \mathrm{C}$ and at $730^{\circ} \mathrm{C}$ during heating followed by $600^{\circ} \mathrm{C}$ and $500^{\circ} \mathrm{C}$ isotherms during its cooling phase. RUN-2 consisted of isotherms over $390^{\circ} \mathrm{C}$ at $500^{\circ} \mathrm{C}, 600^{\circ} \mathrm{C}, 730^{\circ} \mathrm{C}$ and $740^{\circ} \mathrm{C}$ in heating followed by isotherms at $600^{\circ} \mathrm{C}, 500^{\circ} \mathrm{C}$ and $390^{\circ} \mathrm{C}$ during cooling. The goal was to determine the triggering of irradiation damage annealing (damage expected to be higher in this sample amongst all four irradiated samples and thus its annealing behavior more pronounced), the role of dwell time, and the mobilization of transmutation gasses and the influence of irradiation damage on oxidation.

Summarized from Figure 6 are the following: During RUN-1 and over the $600^{\circ} \mathrm{C}$ isotherm during heating one can observe that the irradiated beryllium continues to contract via annealing of both manufacturing defects and irradiation damage manifested in the form of lattice swelling. At $730^{\circ} \mathrm{C}$ the contraction is accelerated (change of slope) and it increases further at $730 \mathrm{oC}$. During the subsequent cycle, RUN-2, and for temperatures up to $600^{\circ} \mathrm{C}$ the irradiated beryllium is stable. As expected, at $700^{\circ} \mathrm{C}$ the slope has reduced (indicating that the dwell time required at the high temperatures of $700^{\circ} \mathrm{C}$ and $730^{\circ} \mathrm{C}$ of $\mathrm{RUN}-1$ were not sufficient to anneal both irradiation damage and pre-existing defects). Important to note is the annealing at $730^{\circ} \mathrm{C}$ of RUN-2 which continues with constant slope owed to the fact that no higher temperature than $730^{\circ} \mathrm{C}$ was experienced prior and that no other competing process is being activated. At the subsequent $740^{\circ} \mathrm{C}$ isotherm, which at the beginning of the dwell experiences a high annealing slope, it undergoes a slope evolution that could indicate two possible causes, either beryllium a saturation of the irradiation-induced damage annealing or that there is a new counteracting process that is both temperature dependent and it induces volumetric swelling. Studies reported in [4, 7] following microstructural analyses showed a clear evolution in bubble growth and He diffusion towards the grain boundaries where the bubbles coalesce above a temperature threshold of $\sim 750^{\circ} \mathrm{C}$. It is therefore concluded from this experimental evidence that the change of slope observed is the result of ${ }^{4} \mathrm{He}$ diffusion and coalescence. The microcracks formed as a result of anisotropic lattice behavior (high stresses developing at these temperatures) further facilitate the bubble formation leading to swelling.

In assessing the proton damage annealing to the volumetric changes observed as a function of annealing temperature depicted in Figure 6 we refer to the works $[10,16]$ on neutron irradiation of $\mathrm{BeO}$ and the lattice parameter recovery that was observed. It was observed in [16] that bulk volumetric changes in $\mathrm{BeO}$ in close agreement with volume changes based on lattice parameters and most importantly that an anisotropic lattice expansion occurs with the c direction being greater than the expansion in the a direction. It was also observed [15] that parameter $\boldsymbol{a}$ annealed steadily and with the high dose specimens annealing at a faster rate than the lower dose specimens. Limited recovery of the $\mathrm{c}$ parameter was observed until temperatures of $800-1000^{\circ} \mathrm{C}$ were reached when a sharp recovery was observed. The behavior of proton-irradiated beryllium seen in Figure 6 is similar to what was observed for the annealing of neutron irradiated $\mathrm{BeO}$ with a parameter recovery occurring throughout the annealing temperature range and $\mathrm{c}$ parameter recovering at much higher rates than $\boldsymbol{a}$ for temperatures $\geq 700^{\circ} \mathrm{C}$. Due to experimental limitations prompted by beryllium safety considerations no temperatures higher that $740^{\circ} \mathrm{C}$ were used for annealing to establish the temperature level for complete recovery of parameters $\boldsymbol{c}$ and $\boldsymbol{a}$ for the proton irradiated beryllium.

The dimensional changes depicted in Figures 7-9 quantify the effect of fluence on the recovery behavior of the irradiated beryllium at lower temperatures (controlled by $\boldsymbol{a}$ lattice parameter) and by annealing of manufacturing defects. Also shown that a "discontinuous" oxidation is taking place in irradiated beryllium 
at temperatures as low as $320^{\circ} \mathrm{C}$. This is manifested by the observed changes that occur in the sample temperature that precisely follow the volumetric change that is experienced which is driven by oxidation (exothermic process).

As it has also been observed in previous studies on neutron irradiated beryllium [Leenars] the high quantity of helium produced through neutron multiplication reactions and trapped in the beryllium lattice or and dislocations during thermal annealing becomes mobile and diffuses to the grain boundaries or/and precipitates into bubbles. It is noted in $[3,4,12]$ that the bubbles observed at the grain boundaries are created by migration of $\mathrm{He}$ atoms to voids and/or interfaces of particles such as $\mathrm{BeO}$ present at the grain boundaries. These gas bubbles, which coarsen and coalesce, induce a swelling of the material. The swelling as a result of migrating and coalescing He is counteracting the lattice recovery that is taking place at the same time. This is evident in Figure 6 at the $740^{\circ} \mathrm{C}$ annealing temperature where there is a slowdown of the c parameter recovery rate and more clearly in Figures 10 and 11(a) where the swelling due to $\mathrm{He}$ gas bubbles at the given fluence begins to reverse the lattice contraction taking place as a result of annealing. As shown in Fig. 10 subsequent annealing at the slightly lower temperature of $730^{\circ} \mathrm{C}$ the kinetics change dramatically in large scale (similar trend is seen for irradiated at different proton fluence and unirradiated beryllium) and differences, driven primarily from oxidation, are observed in a smaller scale (see Figures 11 and 12).

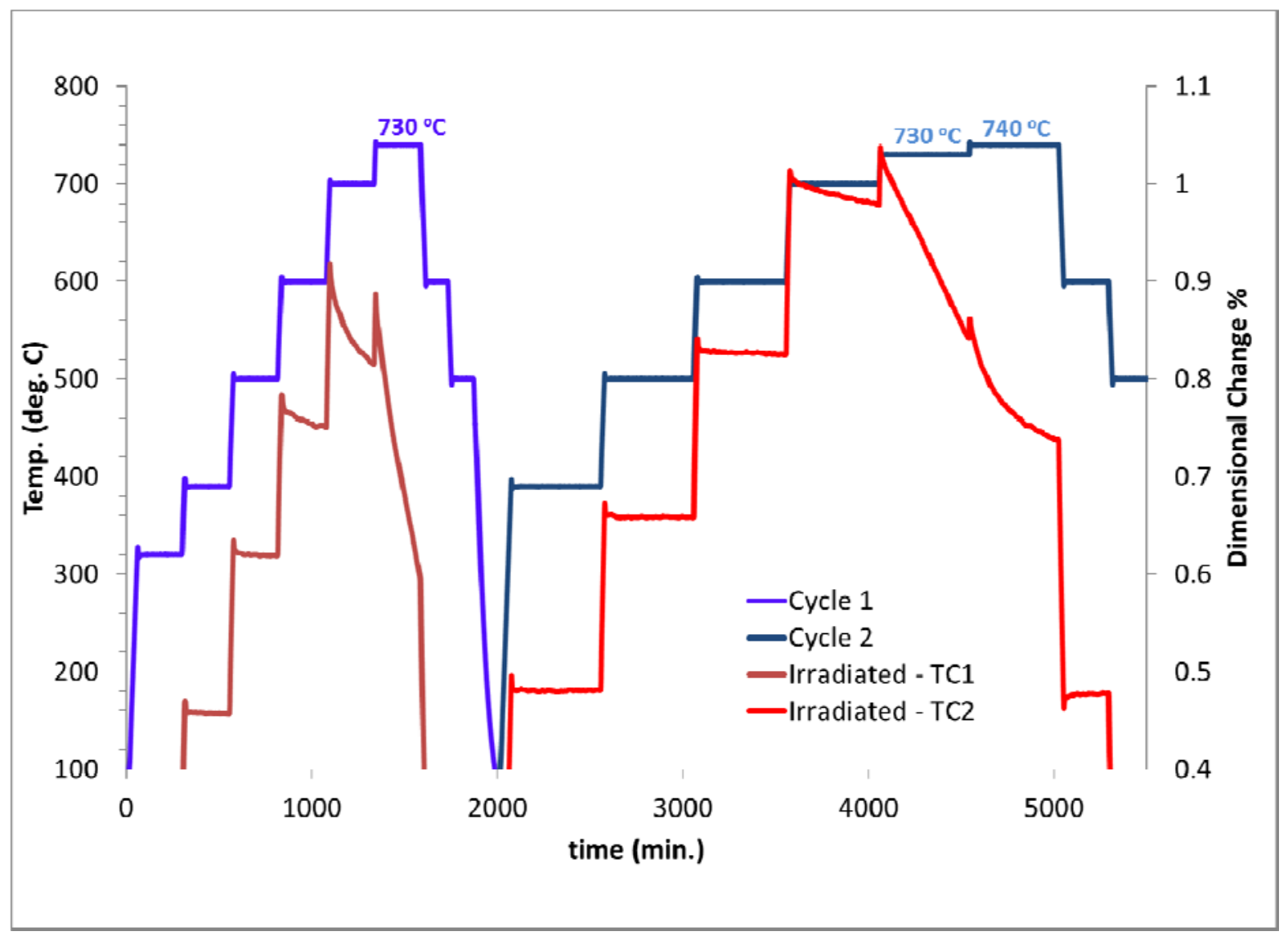

Figure 6: High temperature annealing of proton irradiated beryllium to a fluence of $0.610^{20} \mathrm{p} / \mathrm{cm}^{2}$ over two multi-isotherm cycles. 

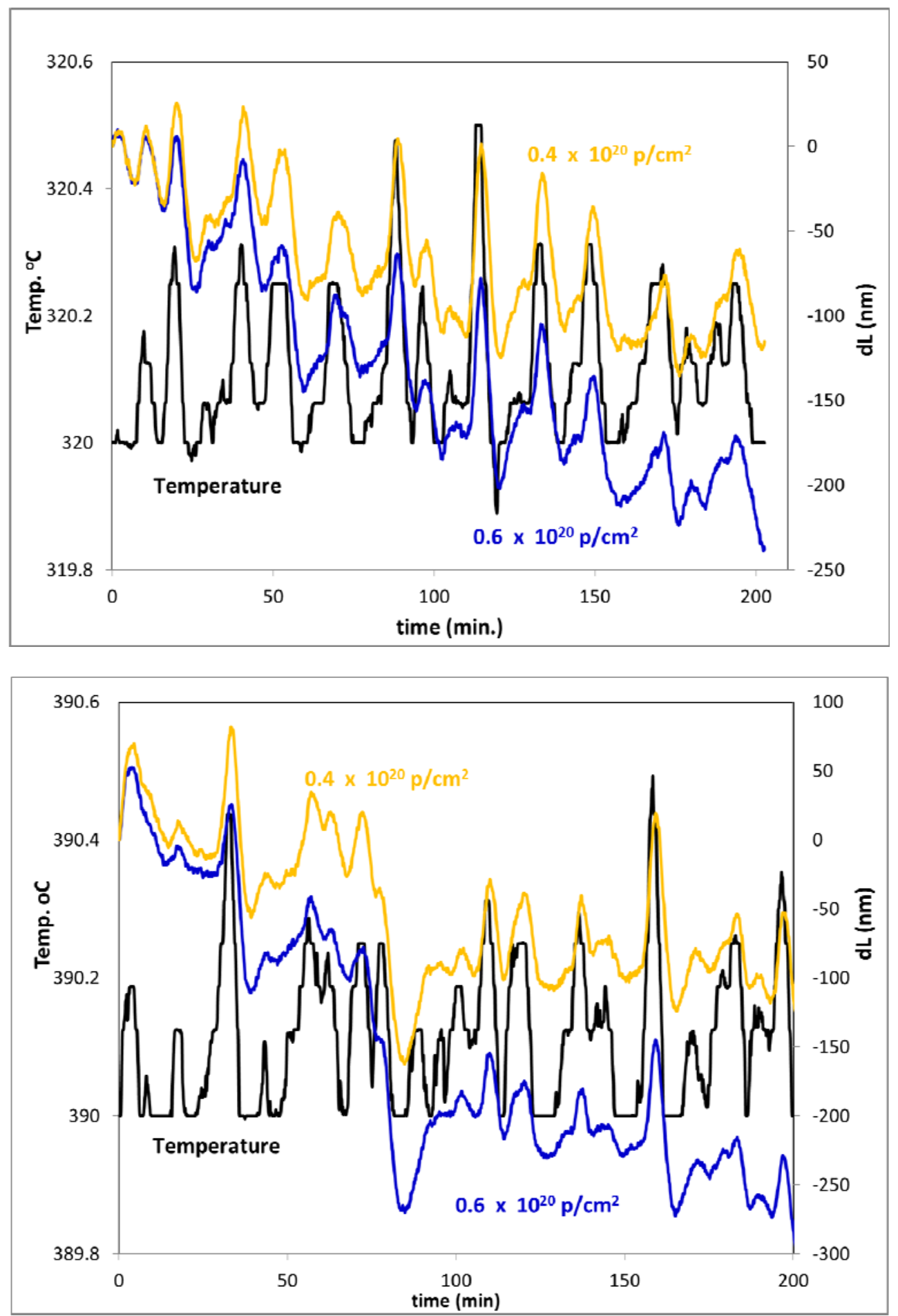

Figure 7: Behavior of irradiated beryllium over two low-temperature isotherms of $320^{\circ} \mathrm{C}$ (top) and $390^{\circ} \mathrm{C}$ (bottom) for two irradiation levels. Depicted are (a) the downward trend indicating lattice irradiationinduced swelling annealing and (b) oxidation behavior with accompanying temperature variation. 
Figure 8: Direct comparison of the dimensional change behavior of beryllium at $390 \mathrm{oC}$ for unirradiated and irradiated $\left(0.1810^{20} \mathrm{p} / \mathrm{cm}^{2}\right)$ beryllium. The dimensional change is shown in nanometers (right axis).

The figure indicates, based on the fluctuation of the sample temperature, that oxidation is triggered at these temperatures even for unirradiated beryllium.
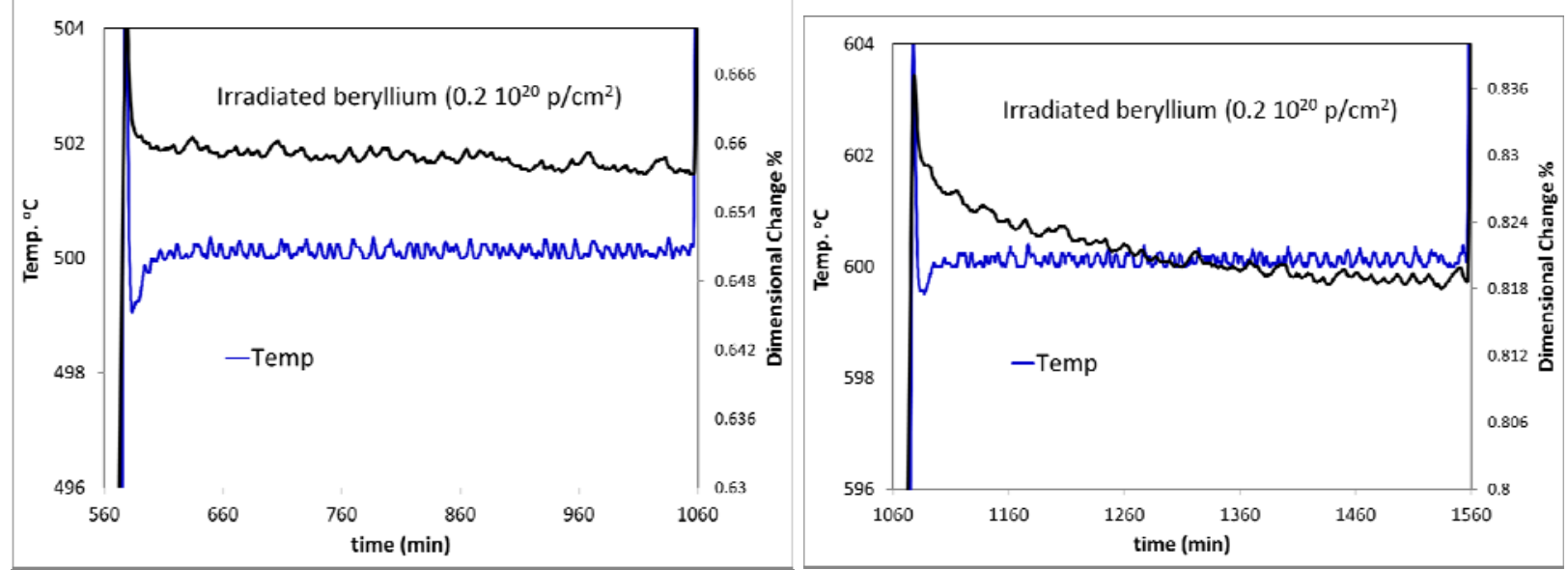

Figure 9: Dimensional change or "contraction" of irradiated beryllium lattice as a result of annealing out of irradiation damage (formation of vacancies and interstitial inducing swelling) following thermal cycling to $600^{\circ} \mathrm{C}$. Shown above is that for temperatures up to thermal cycling temperature the potential annealing remaining are minimal. For isotherms $>600^{\circ} \mathrm{C}$ it is expected that the recovery in the form of 'contraction" of the lattice will be pronounced. 